\title{
PLATELET COUNT AS INFLAMMATORY MARKER IN PEDIATRIC SYSTEMIC LUPUS ERYTHEMATOSUS
}

\author{
Raina Sekar Kinanti ${ }^{1}$, Reni Ghrahani ${ }^{2}$, Sri Suryanti ${ }^{3}$. \\ ${ }^{1}$ Faculty of Medicine, Universitas Padjadjaran, Bandung, Indonesia, \\ ${ }^{2}$ Department of Child Health, Faculty of Medicine, Universitas Padjadjaran, Dr. Hasan Sadikin General \\ Hospital, Bandung, Indonesia, \\ ${ }^{3}$ Department of Anatomic Pathology, Faculty of Medicine, Universitas Padjajaran, Dr. Hasan Sadikin \\ General Hospital, Bandung, Indonesia.
}

\begin{abstract}
Background: Platelets as immune cells have been shown to play several roles in inflammation. Increasing of anti-double stranded DNA (anti-dsDNA) autoantibody levels are commonly used to assess the high disease activity of Systemic Lupus Erythematosus (SLE). Platelet count is a cost effective indicator that can easily be detected as inflammatory marker.
\end{abstract}

Objective: This study aimed to see the correlation between platelet count and anti-dsDNA antibody levels.

Methods: This study was a cross-sectional study using data from medical records involving 41 newly-diagnosed pediatric SLE (pSLE) patients (aged $\leq 18$ years) was conducted at Department of Child Health in our hospital between January $1^{\text {st }} 2018$ and June $30^{\text {th }} 2019$. Platelet count was measured using Sysmex XN analyzer. Anti-dsDNA antibody levels were measured by Standard Enzyme Linked Immunosorbent Assay (ELISA). Spearman's rank correlation and Pearson's chi squared test were performed to analyze the data ( $p<0.05$ is considered significant).

Results: Forty-one pSLE patients were included in this study, consisting of 38 female $(92.7 \%)$ and 3 male $(7.3 \%)$ patients with median age of 15 $(\mathrm{IQR}=13-17)$. The median value of platelet count was $238000 / \mathrm{mm}^{3}(\mathrm{IQR}=$ $\left.152000-355000 / \mathrm{mm}^{3}\right)$. The median value of anti-dsDNA antibody levels was $153.8 \mathrm{IU} / \mathrm{ml}$ (IQR = 30.5-416.2). Platelet count was inversely correlated with anti-dsDNA antibody levels (Spearman correlation Rho $=-0.433, p=0.005$ ). Thrombocytopenia was correlated with rash $(p=0.001)$, fever $(p=0.0002)$, and arthritis $(p=0.001)$.

Conclusion: Decreasing of platelet count can be considered as new parameter in predicting SLE with highly active disease course.

\author{
ARTICLE HISTORY \\ Received 13 October 2020 \\ Accepted 25 January 2021
}

KEYWORDS

\section{Introduction}

Systemic Lupus Erythematosus (SLE) is a systemic autoimmune disorder involving many organs. SLE is marked by several autoantibodies and the major damage in this disease is caused by deposit of immune complex and antibody binding to cells and tissues. ${ }^{1}$ SLE incidence rate in children is $0.5-1: 100,000$ with prevalence $1: 10.000 .^{2}$ In Department of Child Health, Dr. Cipto Mangunkusumo National General Hospital between 1997 to 2007, there were 29 pediatric SLE (pSLE) patients from the total of 36 SLE cases. ${ }^{3}$ Lupus nephritis occur in 50-75\% pSLE patients and considered as significant factor for morbidity and mortality. 4,5

Genetic, immunologic, environmental, and hormonal

Address for Correspondence: Reni Ghrahani, Jalan Pasteur no. 38, Bandung, Indonesia.

Email: renighrahani@yahoo.com (c)2021 Pediatric Oncall factors promote the development of SLE. The failure of self-tolerance in immune system occur in this disease and there is a presence of autoantibody production that is pathogenic toward nucleic acid and its binding protein. ${ }^{1,6}$ Anti-dsDNA is one of the most important autoantibodies that play roles as specific and pathogenic marker in SLE. ${ }^{7}$

Platelet has many roles in immune system during inflammation beside its homeostatic function. ${ }^{8}$ Hematologic abnormalities are common in SLE and one of them is thrombocytopenia that is found to be related with the progressivity of the disease. ${ }^{9}$ Thrombocytopenia in SLE happen as a result of platelet destruction caused by autoantibodymediated reaction. Several studies prove that antidsDNA antibody can cross-react with various epitopes in different proteins. The link between anti-platelet autoantibodies and epitopes mimicking dsDNA that cause thrombocytopenia has not been established. ${ }^{10}$

Thrombocytopenia and high anti-dsDNA antibody 
levels are two of the criteria for active SLE disease based on American College Rheumatology (ACR) 1997 and Systemic Lupus Erythematosus International Collaborating Clinics (SLICC) 2012. ${ }^{11}$ Previous reports shown that there was negative correlation between platelet count and SLE disease activity that was observed by the relationship between platelet count and clinical manifestation in SLE patients based on Systemic Lupus Erythematosus Disease Activity Index (SLEDAI) score. $^{9}$ Anti-dsDNA antibody can also be used as a predictive factor for SLE disease severity. Increased level of anti-dsDNA antibody is also found to be correlated with kidney manifestation in SLE patients. ${ }^{7}$ But anti-dsDNA measurement in Indonesia is only available in several developed cities and the cost is high ${ }^{12}$ whereas platelet count is a routinelyassessed, inexpensive, and easy indicator for detecting inflammation. ${ }^{13}$

This study aimed to determine the correlation between platelet count and anti-dsDNA antibody levels in pSLE patients and determine whether platelet count could be used as new parameter in assessing pSLE patients with high disease activity.

\section{Methods \& Materials}

This study was a cross sectional study conducted between January $1^{\text {st }} 2018$ and June $30^{\text {th }} 2019$ using data from medical records of 41 newly diagnosed pSLE patients (aged $\leq 18$ years) in Dr. Hasan Sadikin Bandung General Hospital. Newly-diagnosed pSLE patients were the patients that had been diagnosed with SLE based on ACR 1997 and SLICC 2012 criteria and had not received treatment according to the protocol. ${ }^{11}$ The exclusion criteria were inaccessible medical records and pSLE patients with secondary infections. The variables in this study were platelet count and anti-dsDNA antibody levels. Platelet count was measured by Sysmex XN analyzer. Thrombocytopenia was defined if platelet count was $<100000 / \mathrm{mm}^{3}$. ${ }^{11}$ Anti-dsDNA antibody level was measured by ELISA. Elevated anti-dsDNA was $>10$ $\mathrm{U} / \mathrm{ml}) .{ }^{14}$ This study also included patient characteristics such as patients' age, gender, chief complaints, and the presence of lupus nephritis as the variables. Lupus nephritis was defined as SLE patients with kidney involvement which is characterized by elevated 24hour urinary protein ( $\geq 500 \mathrm{mg}$ ) or urine protein to creatinine ratio $(\geq 0.5)$ or the presence of red blood cell casts in urine or renal biopsy showed immune complex mediated nephritis with complement deposition. ${ }^{15}$

The permission of this study was approved by Health Research Ethics Committee Faculty of Medicine, Universitas Padjadjaran with ethical number 677/UN6.
Figure 1. Relationship between Platelet Count and Anti-dsDNA Antibody Levels was Linear and Negative

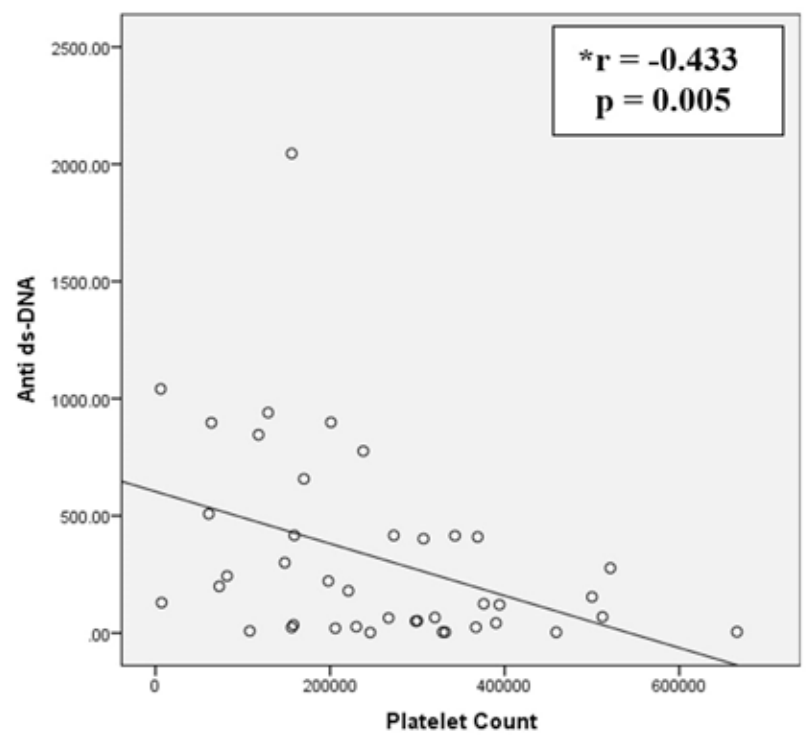

$*_{r}=$ Spearman rank correlation coefficient

$\mathrm{KEP} / \mathrm{EC} / 2019$. Data from medical records of newly diagnosed pSLE patients were used in this study. The correlation of platelet count and anti-dsDNA antibody level was analyzed by Spearman's rank correlation where $p<0.05$ was regarded as statistically significant. The correlation between thrombocytopenia and most presented chief complaints was analyzed by Pearson's chi squared test where $\mathrm{p}<0.05$ was regarded as statistically significant.

\section{Results}

Male:female ratio was 3:38. Median age of patients was 15 years with range of 13-17 years. The most chief complaints presented were rash in $16(39 \%)$ patients, fever in $14(34 \%)$ patients, and arthritis in $11(26 \%)$ patients. Lupus nephritis was present in $17(41.5 \%)$ patients at the time of presentation. The median value of platelet count was $238000 / \mathrm{mm}^{3}$ (IQR $=152000-$ $355000 / \mathrm{mm}^{3}$ ). Six patients had thrombocytopenia. The median value of anti-dsDNA antibody levels was $153.8 \mathrm{IU} / \mathrm{ml}$ (IQR = 30.5-416.2). Thirty-five patients had high titre of anti-dsDNA levels. Platelet count was inversely correlated with anti-dsDNA antibody levels (Spearman correlation Rho $=-0.433, \mathrm{p}=0.005$ ) (Figure 1 ). Thrombocytopenia significantly correlated with rash $(p=0.001)$, fever $(p=0.0002)$, and arthritis $(p=0.001)$

Table 1. Relationship between Thrombocytopenia and Most Chief Complaints Presented

\begin{tabular}{|c|c|c|c|c|c|}
\hline \multirow[t]{2}{*}{ Chief Complaints } & \multicolumn{2}{|c|}{ Thrombocytopenia $(n=6)$} & \multirow[t]{2}{*}{ Total } & \multirow[t]{2}{*}{ OR (95\% CI) } & \multirow[t]{2}{*}{ p Value } \\
\hline & Yes (\%) & No $(\%)$ & & & \\
\hline Rash & 6 & 10 & 16 & - & 0.001 \\
\hline Fever & 6 & 8 & 14 & - & 0.0002 \\
\hline Arthritis & 5 & 6 & 11 & $24.1(2.3-245.9)$ & 0.001 \\
\hline
\end{tabular}


(Table 1). Thrombocytopenia was seen in 3 (7.3\%) children with lupus nephritis which was statistically insignificant $(p=0.646)$.

\section{Discussion}

In this study, most of the pSLE patients were females. This result was similar with the study from Almaani et al. ${ }^{16}$ in Ohio which stated that the female-to-male ratio range between $8: 1$ to $15: 1$. Another study from Sinha et al. ${ }^{17}$ in India stated that $80 \%$ patients that were involved in their study were female. This finding was because of hormonal factors such as sex steroids and prolactin hormones that may increase the number of autoreactive mature B-cell. ${ }^{6}$ The median age of the patients in this study were 15 years. The study from Zhu et al. ${ }^{18}$ found that most of their patients were from adolescent group (12-18 years old). Based on the study from Sinha et al. ${ }^{17}$, the median age of pSLE onset was between 11 and 12 years old and the course was more severe than adult.

The most chief complaints presented in this study were rash, fever, and arthritis. This finding is almost similar with the study from Saleh et al. ${ }^{3}$ which stated that the most clinical manifestations presented in their study were arthritis, rash, and fever. However, a study from Batool et al. ${ }^{19}$ was different with this findings. They stated that most of the clinical manifestations presented in their study were fatigue, fever, and rash. This result might be different because the subject of their study were adults ( $>18$ years old).

Platelet count is an easy and inexpensive indicator that can be conducted as inflammatory marker. The platelet count in this study had the median value of $238000 /$ $\mathrm{mm}^{3}$ and it was still in the normal value based on the ACR 1997 and SLICC 2012 criteria (thrombocytopenia $\left.=<100000 / \mathrm{mm}^{3}\right) \cdot{ }^{11}$ Most of the subjects did not have thrombocytopenia. This might be the result of the subject selection in this study that were only involving the newly-diagnosed pSLE patients. The study from Galanopoulos et al. ${ }^{20}$ stated that thrombocytopenia occur in $20-40 \%$ SLE patients. Based on the study from Fayyaz et al. ${ }^{21}$ in USA, most thrombocytopenia cases in SLE is caused by increase of peripheral platelet destruction which is mediated by antiplatelet antibodies.

Anti-dsDNA antibody is one of the most important autoantibodies that can be used as SLE disease activity marker. It presents in ACR 1997 and SLICC 2012 as one of the diagnostic criteria of SLE. ${ }^{11}$ But in Indonesia, anti-dsDNA measurement is only available in developed cities and is expensive. Farkhati et al $^{22}$ stated that in SLE patients with positive anti-dsDNA levels, severe disease activity was present and they had higher mortality rate. Another study from Dhason et al $^{23}$ revealed that anti-dsDNA antibody level was positive in $83 \%$ of all patients with active lupus and $66 \%$ of them had high titre of anti-dsDNA levels (>10 IU/ml). There was also a significant correlation between high anti-dsDNA titre and disease activity in the active disease group compared to inactive disease and healthy controls in their study $(P<0.001)$.

Inverse correlation was found between platelet count and anti-dsDNA levels in this study. Significant correlation between thrombocytopenia and rash, fever, and arthritis were also found. By this, it can be stated that the higher anti-dsDNA level was correlated with the lower platelet count, and also correlated with the higher is the SLE disease activity based on the chief complaints presented. Study from Galil et al. ${ }^{9}$ found almost similar result which the platelet count had negative correlation with SLEDAI score that reflected the disease activity. Previous study from Zhang et al $^{10}$ suggested that the presence of specific epitope cross-reaction between GPIIIa49-66 and dsDNA could be a mechanism in the development of thrombocytopenia in SLE. Fayyaz et $\mathrm{al}^{21}$ however stated that in SLE patients, almost no binding of platelet glycoproteins were found. Thus, until now, the exact mechanism of the correlation between platelet count and anti-dsDNA antibody is not clear.

In this study, no significant correlation between platelet count and lupus nephritis was found. However, Ktona et $\mathrm{al}^{24}$ found the most common complication in SLEassociated thrombocytopenia was lupus nephritis $(65.7 \%)$ and was 2.9 times higher than the control group. This result might be different because the subjects in their study were adults.

\section{Conclusion}

Based on this study, it is concluded that there is an inverse correlation between platelet count and antidsDNA antibody level in SLE patients and there is a significant correlation between thrombocytopenia and rash, fever, and arthritis. Therefore, decreasing of platelet count can be considered as a new parameter in predicting SLE patients with high disease course.

The limitation of this study was the data collection that were collected retrospectively from secondary data, thus not all subjects had the variables needed.

\section{Acknowledgement}

We would like to thank all departments involved: Department of Child Health and Department of Anatomical Pathology, Universitas Padjadjaran, Dr. Hasan Sadikin Bandung General Hospital.

\section{Compliance with Ethical Standards}

Funding: None

Conflict of Interest: None

\section{References:}

1. Vinay, Abul, Jon. Diseases of the Immune System. In: Robbins and Cotran Pathologic Basis of Disease. 9th editio. Elsevier Health Sciences; 2014. p. 185-264.

2. Lehman, Taber, Nuruzzaman. Systemic Lupus Erythematosus in Childhood and Adolescence. In: Dubois' Lupus Erythematosus and Related Syndromes. Ninth Edit. Elsevier Inc.; 2018. p. 520-31.

3. Saleh A, Kurniati N, Syarif B. Penilaian Aktivitas Penyakit Lupus Eritematosus Sistemik dengan Skor SLEDAI di Departemen Ilmu Kesehatan Anak RSCM. Sari Pediatr. 2014;16(4).

4. Arsita E. Peran Infeksi Sebagai Prediktor Mortalitas pada Pasien Lupus Eritematosus Sistemik yang Dirawat Inap. Universitas Indonesia; 2014.

5. Kasjmir YI, Handono K, Wijaya LK, Hamijoyo L, Albar Z, Kalim $\mathrm{H}$, et al. Rekomendasi Perhimpunan Reumatologi Indonesia untuk Diagnosis dan Pengelolaan Lupus 
Eritematosus Sistemik. 2011. 1-54 p.

6. Bertsias G, Cervera R, Boumpas DT. Systemic Lupus Erythematosus: Pathogenesis and Clinical Features. In: Eular Textbook on Rheumatic Diseases. 2012. p. 476-505.

7. Marpaung B, Patrick J. The relationship between increased levels of Anti- dsDNA with clinical manifestation in patients with SLE in Haji Adam Malik General Hospital Medan. IOP Publ. 2016;125:1-5.

8. Thomas MR, Storey RF. The role of platelets in inflammation. Schattauer. 2015;449-57.

9. Mahfouz S, Galil A, Edrees AM, Khaled A, Aldoobi GS, Elboshy $M$, et al. Prognostic significance of platelet count in SLE patients. Taylor Fr Gr. 2016;7104:1-5.

10. Zhang W, Dang S, Wang J, Nardi MA, Zan H, Casali P, et al. Specific cross-reaction of anti-dsDNA antibody with platelet integrin GPIIIa49-66. HHS Public Access. 2016;43(8):1-15.

11. Lam N-CV, Ghetu M V, Bieniek ML. Systemic lupus erythematosus: Primary care approach to diagnosis and management. Am Fam Physician. 2016;94(4):284-94.

12. Sapartini G, Ghrahani R, Setiabudiawan B. Association between Lymphopenia and Clinical Manifestations, Anti-dsDNA, and Disease Activity in Children with Systemic Lupus Erythematosus. J Allergy Clin Immunol. 141(2):AB119.

13. Balta S, Ozturk C. The platelet-lymphocyte ratio : A simple, inexpensive and rapid prognostic marker for cardiovascular events. Inf Healthc. 2014;1-2.

14. Olson SW, Lee JJ, Prince LK, Baker TP, Papadopoulos P, Edison J, et al. Article Elevated Subclinical Double-Stranded DNA Antibodies and Future Proliferative Lupus Nephritis.
2013;1-7.

15. Pinheiro SVB, Dias RF, Fabiano RCG, Araujo S de A, Simões e Silva AC. Pediatric lupus nephritis. SciELO. 2018;1-15.

16. Almaani S, Meara A, Rovin BH. Update on Lupus Nephritis - Nephrology Rounds. Clin J Am Soc Nephrol. 2017;12:82535.

17. Sinha R, Raut S. Pediatric lupus nephritis: Management update. World J Nephrol. 2017;3(2):16.

18. Zhu J, Wu F, Huang X. Age-related differences in the clinical characteristics of systemic lupus erythematosus in children. Rheumatol Int. 2013;33(1):111-5.

19. Batool S, Ahmad NM, Saeed MA, Farman S. Pattern of initial clinical manifestations of systemic lupus erythematosus in a tertiary care hospital. 2016;32(5):1066-70.

20. Galanopoulos N, Christoforidou A, Bezirgiannidou Z. Lupus thrombocytopenia: pathogenesis and therapeutic implications. Mediterr J Rheumatol. 2017;28(1):20-6.

21. Fayyaz A, Igoe A, Kurien BT, Danda D, James JA, Stafford $\mathrm{HA}$, et al. Haematological manifestations of lupus. $\mathrm{Br}$ Med J. $2015 ; 2: 1-18$.

22. Farkhati MY, Hapsara S, Satria CD. Antibodi AntidsDNA Sebagai Faktor Prognosis Mortalitas pada Lupus Eritematosus Sistemik. Sari Pediatr. 2012;14(2):2-8.

23. Dhason TM, Jayaraj EL, Sankaralingam R. Correlation between anti-dsDNA, complement components C3, C4 and Systemeic Lupus Erythematosus disease activity index. J Immunol Clin Microbiol. 2017;2(3):54-61.

24. Ktona E, Barbullushi M, Backa T, Idrizi A, Shpata V, Roshi E. Evaluation of Thrombocytopenia in Systemic Lupus Erythematosus and Correlation with Different Organs Damages. 2014;26:122-124. 